\title{
Оптимизация параметров фотоприемников дальнего ИК диапазона на основе гетероструктур GaAs/AlGaAs с внутренней фотоэмиссией
}

\author{
Д.Г. Есаев \\ Институт физики полупроводников им. А. В. Ржанова СО РАН, Новосибирск \\ тел:+7 (383) 330-90-29, эл. почта: еsaev@isp.nsc.ru
}

DOI 10.34077/RCSP2019-160

В работе представлены результаты разработки, исследования и оптимизации параметров фотоприемников дальнего ИК диапазона на основе структур $\mathrm{c}$ внутренней фотоэмиссией представленных на рисунке 1 .

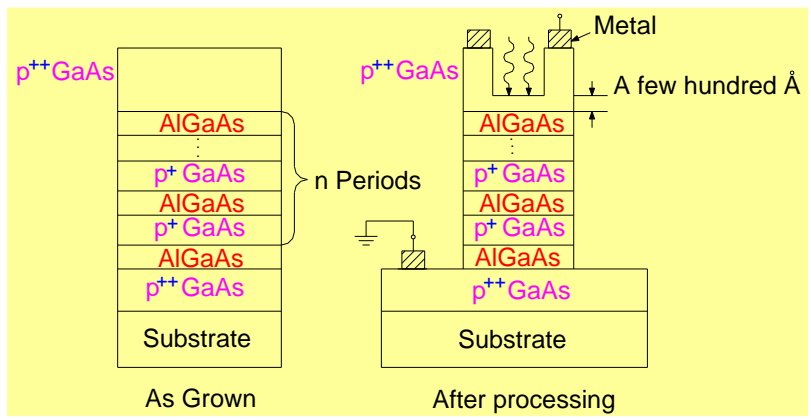

Легированные бериллием слои GaAs служат эмиттерами носителей заряда. Фотовозбужденные в эмиттере носители переносятся через барьер на границе с нелегированными барьерными слоями AlGaAs.

Преимущество данного типа приемников в сравнении с приемниками на основе структур с квантовыми ямами аналогичной архитектуры состоит в:

- возможности регистрации ИК излучения в широком диапазоне, граница спектральной чувствительности может варьироваться от 5 до 200 мкм, путем варьирования состава алюминия в барьерных слоях AlGaAs.

- высокой квантовая эффективности;

- регистрации излучения при прямой засветке без необходимости изготовления дифракционных элементов ввода излучения;

- возможность оптимизации фотоэлектрических параметров с использованием с интерференционных эффектов внутри структуры; [1].

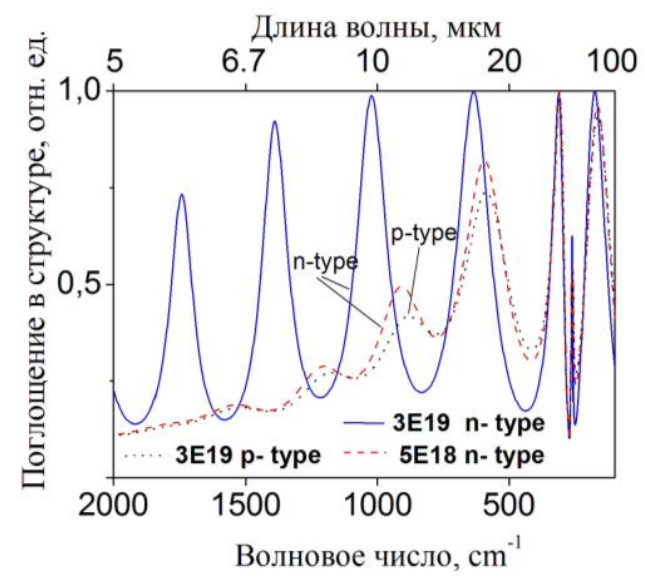

В данной работе рассматриваются структуры с ртипом проводимости в эмитирующих слоях GaAs легированная бериллием. Барьерные слои AlGaAs не легированы.

Одним из путей повышения эффективности данного типа фотоприемников состоит в создании дополнительных условий для максимального поглощения принимаемого излучения.

При этом возможны несколько вариантов: введение дополнительных буферных слоев необходимой конфигурации, использование легированной подложки и другое.

В работе рассматривается первый вариант. Расчетным путем показано, что введение в подложку, перед выращиванием фоточувствительных слоев, буферных зон (spacer) определенной конфигурации приводит к увеличению чувствительности фотоприемников. Результаты расчета приведены на следующем рисунке [2].

На рисунке показано влияние буферных слоев различного типа проводимости, $\mathrm{n}$ и $\mathrm{p}$ типа с разной концентрацией уровня легирования, на поглощение излучения в фоточувствительной структуре.

Полученные результаты показывают возможность увеличения эффективности работы фотоприемников различной модификации и с разной спектральной чувствительностью путем использованием дополнительных буферных слоев.

\section{Лumepamypa}

[1] S. G. Matsik, M. B. M. Rinzan, D. G. Esaev, and A. G. U. Perera, $20 \mu \mathrm{m}$ cutoff heterojunction interfacial work function internal photoemission detectors, 2004, Appl. Phys. Lett., v.84, N 18.

[2] D. G. Esaev, S. G. Matsik, M. B. M. Rinzan, and A. G. U. Perera, Resonant cavity enhancement in heterojunction GaAs/AlGaAs terahertz detectors, 2003, J. Appl. Physics., v. 93, N 4. 